\title{
Accounting
}

\section{An analysis of auditors' perceptions towards artificial intelligence and its contribution to audit quality}

\section{Ibrahim Albawwat $^{\mathrm{a}^{*}}$ and Yaser Al Frijat ${ }^{\mathrm{a}}$}

\section{${ }^{a}$ Tafila Technical University, Jordan}

\section{H R O N I C L E}

\section{Article history:}

Received: November 28, 2020

Received in revised format:

December 282020

Accepted: February 7, 2021

Available online:

February 7, 2021

Keywords:

Auditing

Artificial intelligence

Perceived ease of use

Perceived usefulness

Audit quality

\begin{abstract}
A B S T R A C T
Artificial intelligence (AI) systems have significantly changed the audit process; nevertheless, the AI revolution opponents view this growth as a step-back as many auditors will fail to adapt to this new environment and will drop behind. Our descriptive study examines the perceived ease of use, usefulness, and contribution to the audit quality of different AI's types. To address local audit firms concerns about their readiness to use AI systems in auditing processes and to advance auditing research, we examine whether perceived ease of use, usefulness, and contribution to audit quality vary by AI systems type (Assisted, Augmented, and Autonomous). An online questionnaire was used to collect data from 124 auditors representing local audit firms in Jordan. Our results indicate that auditors perceive Assisted and Augmented AI systems as ease of use in auditing while perceiving Autonomous AI systems as complicated to use. Besides, Auditors are underestimating Autonomous AI systems' capabilities and perceived it as not useful for auditing. The results also reveal a significant difference between the perceived contribution to audit quality by the three AI systems types. This study contributes to the existing literature on AI and auditing by developing and testing a measure for AI systems' perceived contribution to audit quality. This study also provides empirical evidence on how Jordan local firms auditors perceive AI use in auditing.
\end{abstract}

C 2021 by the authors: licensee Growing Science, Canada

\section{Introduction}

Audit firms are making significant investments in cutting-edge technological innovations to enhance the audit process's efficiency and effectiveness (Alles \& Gray, 2019). Specialists gauge that each of the 'Big 4' firms spends $\$ 250$ million every year on artificial intelligence (AI) (Alliott, 2017). AI can be depicted as the development of computer systems that can make enhanced decisions, observe its milieu, and act in a way that minimizes its risk of accomplishing an objective (Guang-huan, 2017). AI can mimic human capacities, such as seeing, hearing, performing logical tests, learning, and solving problems (Li \& Liu, 2020). Also, AI systems can create forecasting models and behavioural standards from big data, making it conceivable to ingest and oversee data and perform analyses (Raphael, 2015). With AI aid, data can be mined and combined, offering a better understanding of the audit process's different stages. An auditor can easily collect data from various sources to derive insights when gathering audit evidence and connect actively back to internal and external parties (Al-Sayyeda et al., 2021). Previous studies indicate three potential benefits from the use of AI in the audit process: (1) generate a better understanding of the client's operations and the associated risks, (2) enhance the process of detecting material misstatements, and (3) advance the communications techniques with those charged with governance (Elliot et al., 2020; Law \& Shen, 2020). An instance regarding the AI application in the audit processes is the contracts review. Machine learning devices permit individuals to examine a larger

* Corresponding author.

E-mail address: al_bawwat2009@yahoo.com (I. Albawwat) 
number of contracts than is possible with a traditional manual review in a shorter period (Schmidt et al., 2020). That is, intelligent devices could precisely analyze lease contracts and extract information using predetermined criteria with an advanced level of accuracy than the human reviewer can (Issa \& Vasarhelyi, 2016).

However, there are some common obstacles concerning the use of AI in auditing: Lack of soft skills to use and manage AI; doubts about compliance with the International Standards on Auditing (ISAs); Lack of widespread trust in AI's capability in an environment that is more and more uncertain (Raphael, 2017). Besides, AI's employment in the audit process presents new risks that may affect audit quality (Ucoglu, 2020). Gartner's 2018 CIO Agenda Survey indicated that AI capabilities should not overestimate as $85 \%$ of AI projects will convey mistaken results due to bias in data, computations, or step up teams. Also, it is anticipated that AI will introduce the risk of not dismissing irrelevant data. Irrelevant data can cause a dilution impact; AI will learn and build patterns based on irrelevant data and lacks predictive and confirmatory values (Greenman, 2017; Raphael, 2017; Schmidt et al., 2020). This inclusion of irrelevant data, in turn, could influence the audit process and, therefore, the audit quality (Abdelraheema et al., 2021).

Previous research has not addressed the auditors' perception regarding using Assisted, Augmented, and Autonomous AI systems in auditing. Our descriptive study fills this void by examining the perceived ease of use, usefulness, and contribution to audit quality of AI systems of different types. Also, we examine the differences in auditors' perceptions across the three type of AI systems. This study's findings have practical implications that could be of interest to many different parties, such as audit firms, AI suppliers, and auditees. These parties can influence AI systems contributions to the audit, thereby enhancing its quality.

\section{Background}

The Cambridge Business English Dictionary defines Artificial intelligence as "computer technology that allows something to be done in a way that is similar to the way a human would do it" (Dictionary, 2015). We believe that "the way a human would do it" would include features such as the ability to observe and perceive the surrounding environment, the capacity to extract data, learn and build patterns from the extracted data, and employ such data and patterns in decision-making processes. Audit firms are presently making significant investments in the development and adoption of AI (Stahl et al., 2017). One of the 4 Big audit firms (i.e. PwC) expects that by 2030, the continuous investments in AI will provide $\$ 15.7$ trillion as global economic growth. It has been reported that three AI types contributed to these gains (Munoko et al., 2020). The first form is called "Assisted AI systems," which assist the individuals in the decision-making process or react to different situations by repeating many of the tasks humans are already doing. These assisted AI systems are typically implemented based on predefined procedures. From this perspective, machines are doing the action, and humans are making decisions. Assisted AI systems are considered "mechanical intelligence" that allows AI to execute day to day tasks. (Munoko et al., 2020). The second form is the "Augmented AI systems," in this type, machines are doing the action, but collaborative human-machine decision-making is required. These systems can interact with their environment and learn from the auditor (Guang-huan, 2017), and therefore, it is considered an "analytical intelligence." In this setting, auditors and AI are co-decision-makers. These augmented AI allow firms to achieve goals that were not achievable before (Munoko et al., 2020). The third form is "Autonomous AI systems." These systems can adapt to diverse circumstances and, in that way, take actions independently, without auditor intervention (Kokina \& Davenport, 2017). In this setting, the auditor passes on decision-making to AI. Autonomous AI systems show both "intuitive" and "empathetic" intelligence. Intuitive intelligence enables the AI to innovatively and effectively amend to new situations. On the other hand, empathetic intelligence allows the AI to recognize individual sentiments, respond suitably, and influence individuals (Munoko et al., 2020). Autonomous AI, which operates without human involvement, requires enhanced intuitive intelligence to handle novel situations and probably even the more sophisticated empathetic intelligence that would permit the AI to interact with individuals successfully (Munoko et al., 2020; Raphael, 2015).

Few research studies have examined the auditors' perceptions of using different AI types in audit engagements with inconsistent results (Issa \& Vasarhelyi, 2016; Kokina \& Davenport, 2017; Moffitt et al., 2018; Munoko et al., 2020). Audit firms' continuous transformation to AI adoption can explain the inconsistency in previous studies' findings and limit their generalizability. Therefore, the current study attempts in the following sections to elicit the Jordan auditors' perceptions towards AI use in auditing in terms of easiness, usefulness, and contribution to audit quality.

\section{Literature Review and Research Questions}

\subsection{Perceived Ease of Use and Usefulness of AI in Auditing}

Introducing new technology and offer it in the markets will not consider an innovation unless the targeted users accept and use it (Mlekus et al., 2020). Before accepting and using new technology, targeted users need to be convinced that this technology will facilitate performing the job and improve work quality (Stancheva-Todorova, 2018). Organizations need to implement new technology in their working processes in order to achieve a competitive advantage. To do so, companies should understand how 
their employees perceive the easiness and usefulness of using the new technology and ensure that their employees can adjust their working techniques to be in line with the technology they seek to implement (Mlekus et al., 2020). The elements of the Technology Acceptance Model (TAM) can be used to measure the auditor's perceived ease of use (PEOU) and perceived usefulness (PU) concerning AI. TAM is extensively used to predict technology acceptance behaviours (Janvrin et al., 2008). Davis (1989) proposed PEOU and PU as two primary beliefs that drive new technologies' acceptance. PEOU is the level to which a prospective user perceives new technology adoption as effortless, significantly more straightforward, and user-friendly. On the other hand, PU is a user's perception that new technology will enhance quality and boost job performance. PEOU and PU set up the end user's beliefs and attitudes regarding the new technology, which will predict acceptance and usage (Davis, 1989). Consequently, the current study proposes the following research questions (RQs):

RQ1: What is the perceived ease of use of each AI type in auditing?

RQ2: Is there a significant difference in the perceived ease of use between the types of AI (Assisted/ Augmented/ Autonomous) RQ3: What is the perceived usefulness of each AI type in auditing?

RQ4: Is there a significant difference in the perceived usefulness between the types of AI (Assisted/ Augmented/ Autonomous)?

\subsection{Perceived Contribution of AI to Audit Quality}

AI use in the audit of financial statements could influence the audit quality. For instance, a board member of the Public Company Accounting Oversight Board (PCAOB) indicated that auditors should not be over-relied on AI tools as the tools are not alternative for the auditor's professional skepticism, judgment, and knowledge (Harris, 2017). Audit quality is of supreme importance for auditors; it reflects objectivity and communicates auditors' credibility and is considered the cornerstone of auditing standards that govern the audit's engagements (Abdullah, 1982; Fanani et al., 2020; FRC, 2020). Consequently, AI biases can be seen as a constraint on AI's employment in audit processes as it may influence the audit quality. Ultimately, AI is built upon codes and is subject to be a mirror of the programmer's biases. Moreover, if the coding information lacks the qualitative characteristics, the neural network technology's limitations underpinning AI's deep learning could raise AI biases to the peak point (Janvrin et al., 2008; Solaimani et al., 2020). An instance of AI biases is the AI tools used to rank New York City landlords according to the level of care of properties, which was revealed by an audit to be negatively influenced by the reliedon biased inspection reports (Hempel, 2018). Thus, the current study's fifth and sixth research questions (RQs) are:

RQ5: What is the perceived contribution of each AI type usage to audit quality?

RQ6: Is there a significant difference in the perceived contribution to audit quality between AI types (Assisted/ Augmented/ Autonomous)?

\section{Research methodology}

\subsection{Questionnaire Development and Data Collection}

The present study employed a questionnaire survey to collect data. The questionnaire consisted of three sections in addition to the introductory paragraph. The introductory paragraph illustrates the purpose of the study and defines some terms used in the questionnaire. Section $\mathrm{C}$ asked questions about educational qualifications, professional certificates, and experience. Section A and B were measuring three variables based on previous studies and professional reports. More specifically, perceived ease of use and usefulness (12 items) adopted from (Davis, 1989) and modified and measured using a 5-point Likert scale (1 strongly disagree -5 strongly agree) as follows:

\begin{tabular}{|c|c|c|}
\hline \multicolumn{2}{|r|}{ Items for perceived ease of use } & Items for perceived usefulness \\
\hline 1. & $\begin{array}{l}\text { Learning to operate AI systems and tools in auditing would be easy for } \\
\text { me. }\end{array}$ & $\begin{array}{l}\text { Using AI systems and tools in my future auditing job would enable me } \\
\text { to accomplish tasks more quickly. }\end{array}$ \\
\hline 2. & $\begin{array}{l}\text { I would find it easy to get AI systems and tools to do what I want it to } \\
\text { do in auditing. }\end{array}$ & $\begin{array}{l}\text { Using AI systems and tools would improve my future job performance } \\
\text { in auditing. }\end{array}$ \\
\hline 3. & $\begin{array}{l}\text { My interaction with AI systems and tools in auditing would be } \\
\text { clear/understandable. }\end{array}$ & $\begin{array}{l}\text { Using AI systems and tools in my future auditing job would increase } \\
\text { my productivity. }\end{array}$ \\
\hline 4. & $\begin{array}{l}\text { I would find AI systems and tools in auditing to be flexible to interact } \\
\text { with. }\end{array}$ & $\begin{array}{l}\text { Using AI systems and tools would enhance my effectiveness of the job } \\
\text { in auditing. }\end{array}$ \\
\hline 5. & $\begin{array}{l}\text { It would be easy for me to become skillful with AI systems and tools } \\
\text { in auditing. }\end{array}$ & $\begin{array}{l}\text { Using AI systems and tools would make it easier to do my future job } \\
\text { in auditing. }\end{array}$ \\
\hline 6. & I would find AI systems and tools in auditing easy to use. & I would find AI systems and tools useful in my future job in auditing. \\
\hline
\end{tabular}

Items for measuring the contribution of AI use in an audit-to-audit quality (11 items) were measured using a 5-point Likert scale (1 strongly disagree -5 strongly agree). These items adopted with some modification from the FCR report on "The Use of Technology in the Audit of Financial Statements" (FRC, 2020, p. 4) as follows: 


\begin{tabular}{|c|c|c|c|}
\hline 1. & $\begin{array}{l}\text { Using AI systems and tools in auditing will aid my professional } \\
\text { skepticism }\end{array}$ & 7. & $\begin{array}{l}\text { Using AI systems and tools in auditing will enable me to perform } \\
\text { tests on large or complex datasets where a manual approach would } \\
\text { not be feasible }\end{array}$ \\
\hline 2. & $\begin{array}{l}\text { Using AI systems and tools in auditing will automate routine audit } \\
\text { processes and procedures, allowing more time to focus on areas of } \\
\text { significant judgment }\end{array}$ & 8. & $\begin{array}{l}\text { Using AI systems and tools in auditing will enable the independent } \\
\text { reperformance of complex calculations and modelling }\end{array}$ \\
\hline 3. & $\begin{array}{l}\text { Using AI systems and tools in auditing will deepen my understanding } \\
\text { of the entity and its processes }\end{array}$ & 9. & $\begin{array}{l}\text { Using AI systems and tools in auditing will improve consistency and } \\
\text { central oversight in group audits }\end{array}$ \\
\hline 4. & $\begin{array}{l}\text { Using AI systems and tools in auditing will facilitate robust risk } \\
\text { assessment through the analysis of entire populations }\end{array}$ & 10. & $\begin{array}{l}\text { Using AI systems and tools in auditing will identify instances of } \\
\text { potential fraud }\end{array}$ \\
\hline 5. & $\begin{array}{l}\text { Using AI systems and tools in auditing will enable ongoing risk } \\
\text { assessment throughout the audit process }\end{array}$ & 11. & $\begin{array}{l}\text { Using AI systems and tools in auditing will identify unusual patterns } \\
\text { and exceptions that might not be discernible using more traditional } \\
\text { audit techniques }\end{array}$ \\
\hline 6. & $\begin{array}{l}\text { Using AI systems and tools in auditing will facilitate the focus of audit } \\
\text { testing on the areas of highest risk through stratification of large } \\
\text { populations }\end{array}$ & & \\
\hline
\end{tabular}

Three auditors and three academics examined the questionnaire to ensure its validity. The questionnaire was then pilot tested by seven auditors. Accordingly, minor changes were made to the wording of some items. However, two hundred fifty questionnaires were distributed online to auditors from local firms in Jordan. A total of 124 usable questionnaires were returned and used for the analysis, representing $50 \%$ of the total distributed questionnaires which is an acceptable response rate (Kotrlik \& Higgins, 2001).

\subsection{Data Analysis}

The Statistical Package for Social Sciences software (SPSS) was used to analyze the collected data. After we screened and cleaned the data, we ran Cronbach's alpha to estimate the reliability according to the inter-correlations between the questionnaire's measurement items (Burns \& Burns, 2008). Cronbach's alpha for all constructs was more than the acceptable value of 0.70 . Thus, reliability is supported for all constructs in the current study. Statistical procedures used include descriptive analysis, a one-sample t-test to check for a significant difference from the midpoint of the rating scale, and one-way repeated measures ANOVA (Pallant, 2011) to compare scores recorded on the three types of AI systems (Assisted, Augmented, systems, and Autonomous).

\section{Results}

\subsection{Respondents' Profile}

In this study, the participants (Auditors) were asked to give some information about their education level, the professional certificates they hold, and the years of experience as an auditor. Table 1 shows that $16.9 \%$ of the respondents hold diplomas or lower certificates, $64.5 \%$ hold bachelor degrees representing most of the respondents, $15.3 \%$ have a master degree, and the remaining 3.2\% hold a PhD. The majority of the respondents $(91.9 \%)$ have the Jordanian Certified Public Accountant (JCPA) certificate. The remaining 10 participants were qualified as Certified Public Accountant (CPA) from the United States of America, and by the Association of Chartered Certified Accountants (ACCA) in the United Kingdom. Regarding the experience, 70 participants had 2-4 years experience, which represents approximately $56.5 \%$ of the respondents. Among the respondents, 6 $(4.8 \%)$ are working as auditors for less than two years. Also, 38 EAs had an experience of 5 to 10 years, and the remaining $8.02 \%$ had an experience of more than ten years.

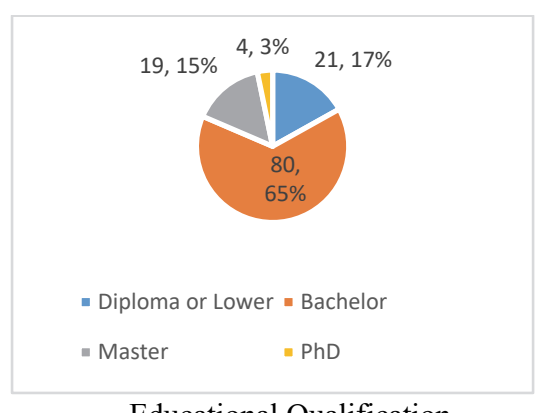

Educational Qualification

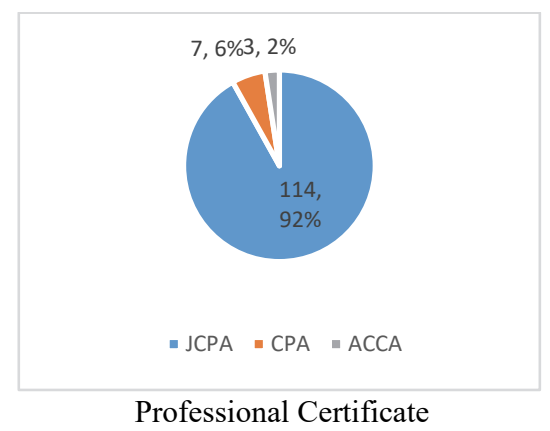

Fig. 1. Profile of the respondents

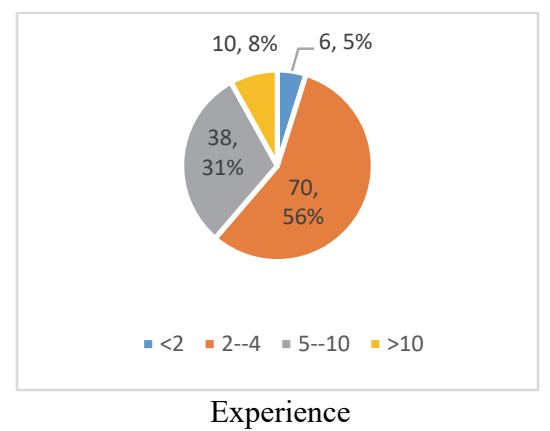

Experience 


\subsection{Perceived Ease of Use and Usefulness of AI in Auditing}

As noted earlier, we find literature and professional reports reported three types of AI that could be used in auditing processes. Therefore, to address RQ1 and RQ3, we report results grouped by the type of AI systems. Descriptive statistics, shown in Table 1 , indicate that the perceived ease of using the different types of AI varies significantly from the midpoint (3). For instance, respondents perceived ease of use of Assisted and Augmented AI systems in auditing as moderately high (means ranged from 3.73 to 3.84 with a significant p-value of t-test) while perceiving Autonomous AI systems as not ease of use (mean of 2.69 which is lower than the midpoint (3) with a significant p-value of t-test). Similarly, participants assigned the highest perceived usefulness ratings to the Assisted AI systems (mean of 3.99 with a significant p-value of t-test) followed by the Augmented AI systems (mean of 3.01 with a significant p-value of t-test). Auditors perceived Autonomous AI systems as not useful for auditing. A possible explanation of such perception could be linked to a potential underestimating of Autonomous AI systems' capabilities by auditors.

Table 1

Perceived ease of use and usefulness

\begin{tabular}{|c|c|c|c|c|}
\hline Type of AI & Perceptions & Mean & Std. Deviation & P-value of t-test \\
\hline \multirow{2}{*}{ Assisted AI systems } & Perceived Ease of Use & 3.7270 & 0.95121 & $.000 *$ \\
\hline & Perceived Usefulness & 3.9907 & 1.01878 & $.000^{*}$ \\
\hline \multirow{2}{*}{ Augmented AI systems } & Perceived Ease of Use & 3.8407 & 0.95380 & $.000^{*}$ \\
\hline & Perceived Usefulness & 3.0056 & 0.66814 & $.000 *$ \\
\hline \multirow{2}{*}{ Autonomous AI systems } & Perceived Ease of Use & 2.6858 & 0.84463 & $.000^{*}$ \\
\hline & Perceived Usefulness & 2.2528 & 0.63896 & $.000 *$ \\
\hline
\end{tabular}

*P-value associated with the t-test is significant at $\mathrm{p}<0.05$

To answer the RQ2 and RQ4, we conducted a one-way repeated measures ANOVA to compare scores on the perceived ease of use and usefulness recorded on the three types of AI systems (Assisted, Augmented, systems, and Autonomous). The means and standard deviations already are presented in Table 1. As shown in Table 2, the type of AI systems significantly affected the auditor perception towards ease of use and usefulness. More specifically, there was a significant difference in the scores means of perceived ease of use of Assisted and Augmented AI systems from the mean of Autonomous AI systems, while were not between Assisted and Augmented AI systems. Likewise, the results indicated significant differences in the perceived usefulness scores between all the three types of AI systems suggesting that auditors perceive each type of AI systems has a different level of usefulness for auditing.

Table 2

One-way repeated measures ANOVA

\begin{tabular}{|c|c|c|c|}
\hline Perceived ease of use & Perceived ease of use & Mean Difference & Sig. \\
\hline \multirow[t]{2}{*}{ Assisted AI systems } & Augmented AI systems & -.114 & 1.000 \\
\hline & Autonomous AI systems & $1.041^{*}$ & .000 \\
\hline \multirow[t]{2}{*}{ Augmented AI systems } & Assisted AI systems & .114 & 1.000 \\
\hline & Autonomous AI systems & $1.155^{*}$ & .000 \\
\hline \multirow{2}{*}{ Autonomous AI systems } & Assisted AI systems & $-1.041^{*}$ & .000 \\
\hline & Augmented AI systems & $-1.155^{*}$ & .000 \\
\hline Perceived Usefulness & Perceived Usefulness & Mean Difference & Sig. \\
\hline \multirow{2}{*}{ Assisted AI systems } & Augmented AI systems & $.985^{*}$ & .000 \\
\hline & Autonomous AI systems & $1.738^{*}$ & .000 \\
\hline \multirow[t]{2}{*}{ Augmented AI systems } & Assisted AI systems & $-.985^{*}$ & .000 \\
\hline & Autonomous AI systems & $.753^{*}$ & .000 \\
\hline \multirow[t]{2}{*}{ Autonomous AI systems } & Assisted AI systems & $-1.738^{*}$ & .000 \\
\hline & Augmented AI systems & $-.753^{*}$ & .000 \\
\hline
\end{tabular}

*The mean difference is significant at the 0.05 level.

\subsection{Perceived Contribution of AI to Audit Quality}

Table 3 shows the descriptive statistics relied-upon in answering RQ5. Auditors perceive all AI types as significantly contributing to audit quality (all means are above the midpoint with a significant p-value of t-test). However, AI's perceived contribution to audit quality varies according to the type of AI. More specifically, Assisted AI systems had the highest level of contribution to audit quality with a mean of (3.45), followed by the Augmented AI systems (mean of 3.25). Concurrently, respondents perceive contribution to audit quality by Autonomous AI systems to be lower than other AI types (mean of 3.1). 


\section{Table 3}

Perceived contribution of AI systems to audit quality

\begin{tabular}{llc}
\hline \multicolumn{1}{c}{ Type of AI } & Mean & Std. Deviation \\
\hline Assisted AI systems & 3.4450 & 0.56111 \\
Augmented AI systems & 3.2445 & 0.62225 \\
Autonomous AI systems & 3.0955 & 0.51860 \\
\hline *P
\end{tabular}

*P-value associated with the t-test is significant at $\mathrm{p}<0.05$

RQ6 was about the difference in the perceived contribution to audit quality between AI types (Assisted/ Augmented/ Autonomous). The one-way repeated measures ANOVA test results in Table 4 reveal a significant difference between the perceived contribution to audit quality by Assisted and Augmented AI systems (mean difference was significant at $\mathrm{P}<0.05$ ). There was also a significant difference between Assisted and Autonomous AI systems (mean difference was significant at $\mathrm{P}<$ 0.05 ) but not between Augmented and Autonomous AI systems (mean difference was not significant, $\mathrm{P}>0.05$ ).

\section{Table 4}

One-way repeated measures ANOVA for perceived contribution to audit quality

Perceived Contribution to Audit Quality

Perceived Contribution to Audit Quality

Mean Difference

Sig.

\begin{tabular}{llcc}
\hline Assisted AI systems & Augmented AI systems & $.200^{*}$ & .041 \\
& Autonomous AI systems & $.350^{*}$ & .000 \\
\hline Augmented AI systems & Assisted AI systems & $-.200^{*}$ & .041 \\
& Autonomous AI systems & .149 & .162 \\
\hline Autonomous AI systems & Assisted AI systems & $-.350^{*}$ & .000 \\
& Augmented AI systems & -.149 & .162 \\
\hline
\end{tabular}

*The mean difference is significant at the 0.05 level.

\section{Discussion, Conclusions, and Future Research}

AI systems have significantly changed the audit process; nevertheless, few research studies have examined auditors' perceptions across AI types. Our descriptive study fills this void by examining the perceived ease of use, perceived usefulness, and perceived contribution to audit quality for the three types of AI systems. Results indicate that auditors perceive Assisted and Augmented AI systems as easy to use in auditing while perceiving Autonomous AI systems as not ease of use. These results provided insights into the acceptance of AI systems by type. When adopting AI systems, ease of use is essential for auditors to accept these systems. If auditors are not comfortable using such systems, they are much less likely to use it, even when useful to their firms. Also, we found that the type of AI systems significantly affected the auditor perception towards ease of use. The level of perceived ease of use assigned by auditors to the Assisted and Augmented AI systems was significantly different from that assigned to Autonomous AI systems. At the same time, auditors reveal no significant difference in perceived ease of use for Assisted and Augmented AI systems. Accordingly, audit firms' training programs should focus on eliminating auditors' concerns about using Autonomous AI systems and developing their employees' skills to ensure organizational talent as developed today's skills will become inefficient in the Autonomous era. Likewise, auditors perceived the Assisted AI systems as more useful in auditing and significantly different from other types. Augmented AI systems are the second in terms of usefulness to auditing. However, auditors perceived Autonomous AI systems as not useful for auditing. Thus, it can be argued that auditors are underestimating the Autonomous AI systems' capabilities. This perception also implies that auditors are not confident in the Autonomous AI systems' ability to improve the audit processes' efficiency and effectiveness. We expect that this perception will last until local audit firms incorporate Autonomous AI systems in their audit; at that time, the auditor can see the usefulness of Autonomous AI systems and how it will enhance the audit process. Other significant findings that auditors perceive all AI types as significantly contributing to audit quality. Assisted AI systems had the highest contribution to audit quality, followed by the Augmented AI systems. Concurrently, respondents perceive contribution to audit quality by Autonomous AI systems to be lower than other AI types. The results also reveal a significant difference between the perceived contribution to audit quality by Assisted and Augmented AI systems, Assisted and Autonomous AI systems, and not between Augmented and Autonomous AI systems. A possible justification for not perceiving a significant difference between Augmented and Autonomous AI systems regarding contribution to audit quality, is that when auditors use Autonomous systems, they pass on to AI the whole decision-making process and a significant part of it in case of Augmented AI systems. In this setting, the two systems are a source of the audit-related decisions and could render insignificantly different audit quality levels. It is anticipated that Assisted AI systems had the highest perceived contribution to audit quality due to the lack of a well designed ethical and social framework for Autonomous AI systems to operate within the rule of law's bounds.

The current study is not free of limitations. First, the developed scale for AI systems' perceived contribution to audit quality needs additional testing to increase its generalizability. Data for this study was from local audit firms through an online survey, so the generalizability of the results to populations from other countries is unknown. Future research might be conducted using 
another sample, preferably internationally, to assess the generalizability of AI systems' perceived contribution to audit quality scale developed and tested in this study. Future studies should also design advanced training to enhance Auditors' perceptions of ease of use and perceived usefulness as a critical path to accept and use AI systems. This study should be replicated in other professions to verify AI systems' contribution to their job quality. Notwithstanding these limitations, our results provide important insights for local audit firms into how their auditors currently perceive AI systems.

\section{References}

Abdelraheem, A., Hussaien, A., Mohammed, M., \& Elbokhari, Y. (2020). The effect of information technology on the quality of accounting information. Accounting, 7(1), 191-196.

Abdullah, K. A. (1982). The audit profession in Jordan and Kuwait: A comparative analytical study. Dirasat Journal, 9(2), 131151.

Alles, M. G., \& Gray, G. L. (2020). Will the medium become the message? A framework for understanding the coming automation of the audit process. Journal of Information Systems, 34(2), 109-130.

Al-Sayyed, S., Al-Aroud, S., \& Zayed, L. (2020). The effect of artificial intelligence technologies on audit evidence. Accounting, $7(2), 281-288$.

BAI, G. H. (2017). Research on the Application and Influence of Auditing Artificial Intelligence. DEStech Transactions on Social Science, Education and Human Science, (eiem).

Burns, R. P., \& Burns, R. (2008). Business research methods and statistics using SPSS. Sage.

Davis, F. D. (1989). Perceived usefulness, perceived ease of use, and user acceptance of information technology. MIS Quarterly, $13(3), 319-340$.

Dictionary, C. (2015). Cambridge dictionaries online.

Elliot, V. H., Paananen, M., \& Staron, M. (2020). Artificial intelligence for decision-makers. Journal of Emerging Technologies in Accounting, 17(1), 51-55.

Fanani, Z., Budi, V., \& Utama, A. (2020). Specialist tenure of audit partner and audit quality. Accounting, 7(3), 573-580.

FRC (2020). AQR The Use of Technology in the Audit of Financial Statements March 2020. Retrieved from Financial Reporting Council:

Review_Technology_20.pdf

Greenman, C. (2017). Exploring the impact of artificial intelligence on the accounting profession. Journal of Research in Business, Economics and Management, 8(3), 1451.

Harris, S. B. (2017). Technology and the Audit of Today and Tomorrow. Hentet, 5, 2018.

Hempel, J. (2018). Want to prove your business is fair? Audit your algorithm. Wired, 5 September.

Issa, H., Sun, T., \& Vasarhelyi, M. A. (2016). Research ideas for artificial intelligence in auditing: The formalization of audit and workforce supplementation. Journal of Emerging Technologies in Accounting, 13(2), 1-20.

Janvrin, D., Bierstaker, J., \& Lowe, D. J. (2008). An examination of audit information technology use and perceived importance. Accounting Horizons, 22(1), 1-21.

Kokina, J., \& Davenport, T. H. (2017). The emergence of artificial intelligence: How automation is changing auditing. Journal of Emerging Technologies in Accounting, 14(1), 115-122.

Kotrlik, J. W. K. J. W., \& Higgins, C. C. H. C. C. (2001). Organizational research: Determining appropriate sample size in survey research appropriate sample size in survey research. Information Technology, Learning, and Performance Journal, $19(1), 43$.

Law, K., \& Shen, M. (2020). How Does Artificial Intelligence Shape the Audit Industry?. Available at SSRN 3718343.

Li, Q., \& Liu, J. (2020). Development of an intelligent NLP-based audit plan knowledge discovery system. Journal of Emerging Technologies in Accounting, 17(1), 89-97.

Mlekus, L., Bentler, D., Paruzel, A., Kato-Beiderwieden, A. L., \& Maier, G. W. (2020). How to raise technology acceptance: user experience characteristics as technology-inherent determinants. Gruppe. Interaktion. Organisation. Zeitschrift für Angewandte Organisationspsychologie (GIO), 51(3), 273-283.

Moffitt, K. C., Rozario, A. M., \& Vasarhelyi, M. A. (2018). Robotic process automation for auditing. Journal of Emerging Technologies in Accounting, 15(1), 1-10.

Munoko, I., Brown-Liburd, H. L., \& Vasarhelyi, M. (2020). The Ethical Implications of Using Artificial Intelligence in Auditing. Journal of Business Ethics, 1-26.

Pallant, J. (2011). Survival manual. A step by step guide to data analysis using SPSS.

Raphael, J. (2015). How artificial intelligence can boost audit quality. CFO Magazine (CFO. com), June, 15.

Raphael, J. (2017). Rethinking the Audit: Innovation Is Transforming How Audits Are Conducted-and Even What It Means to Be an Auditor. Journal of Accountancy, 223(4), 28.

Schmidt, P. J., Church, K. S., \& Riley, J. (2020). Clinging to excel as a security blanket: investigating accountants' resistance to emerging data analytics technology. Journal of Emerging Technologies in Accounting, 17(1), 33-39.

Solaimani, R., Mohammed, S., Rashed, F., \& Elkelish, W. W. (2020). The Impact of Artificial Intelligence on Corporate Control. Corporate Ownership \& Control, 17(3), 171-178. 
Stancheva-Todorova, E. P. (2018). How artificial intelligence is challenging accounting profession. Journal of International Scientific Publications Economy \& Business, 12, 126-141.

Ucoglu, D. (2020). Effects of artificial intelligence technology on accounting profession and education. Pressacademia, 11, 1621.

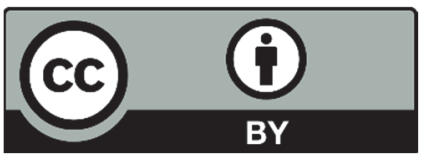

(C) 2021 by the authors; licensee Growing Science, Canada. This is an open access article distributed under the terms and conditions of the Creative Commons Attribution (CC-BY) license (http://creativecommons.org/licenses/by/4.0/). 